
\title{
$\angle S$ Research Square \\ Spectrum Sensing to Detect N-Number of Primary Users Using N-Number Secondary Users by Applying Support Vector Machine.
}

venkateshkumar Udayamoorthy ( $\sim$ uvenkatesh2002@gmail.com )

Sri Krishna College of Technology https://orcid.org/0000-0002-4950-3069

Ramakrishnan Srinivasan

Dr Mahalingam College of Engineering and Technology

\section{Research Article}

Keywords: cooperative spectrum sensing, classification, fusion centre, kernel, support vector machine

Posted Date: March 24th, 2021

DOl: https://doi.org/10.21203/rs.3.rs-218297/v1

License: (c) (1) This work is licensed under a Creative Commons Attribution 4.0 International License.

Read Full License 


\section{Abstract}

In this paper, a cooperative spectrum sensing (CSS) model is proposed to sense $n$-number of primary users (PUs) using n-number secondary users (SUs) in a sequence by applying support vector machine (SVM) algorithm using three different kernels namely linear, polynomial and radial basis function (RBF) respectively. In this method, fusion centre (FC) instructs all the SUs through control channel, which PU is to be sensed by sending a pre-defined primary user identification code (PUid) and each SU sense the $\mathrm{K}^{\text {th }}$ PU spectrum information and stored in a database at FC. SU transmits a bit ' 0 ' or bit ' 1 ' along with PU sensing information to the FC to indicate whether it needs a spectrum band to transmit the data or not. SU add two identification codes along with sensing information to the FC which indicates that from which SU the sensing information received and which PU is sensed by the SU. For simulation 500 data samples are used and the simulation results show an accuracy of $96 \%$ and false alarm value of $1.3 \%$ in classifying the SU sensing information at FC using RBF kernel. Another method is proposed with multiclass classification by applying SVM algorithm using RBF kernel. The confusion region class is classified with zero false alarm percentage and achieves an accuracy of $99.3 \%$ in classifying the SU sensing information at FC.

\section{Full Text}

Due to technical limitations, full-text HTML conversion of this manuscript could not be completed. However, the latest manuscript can be downloaded and accessed as a PDF.

\section{Figures}




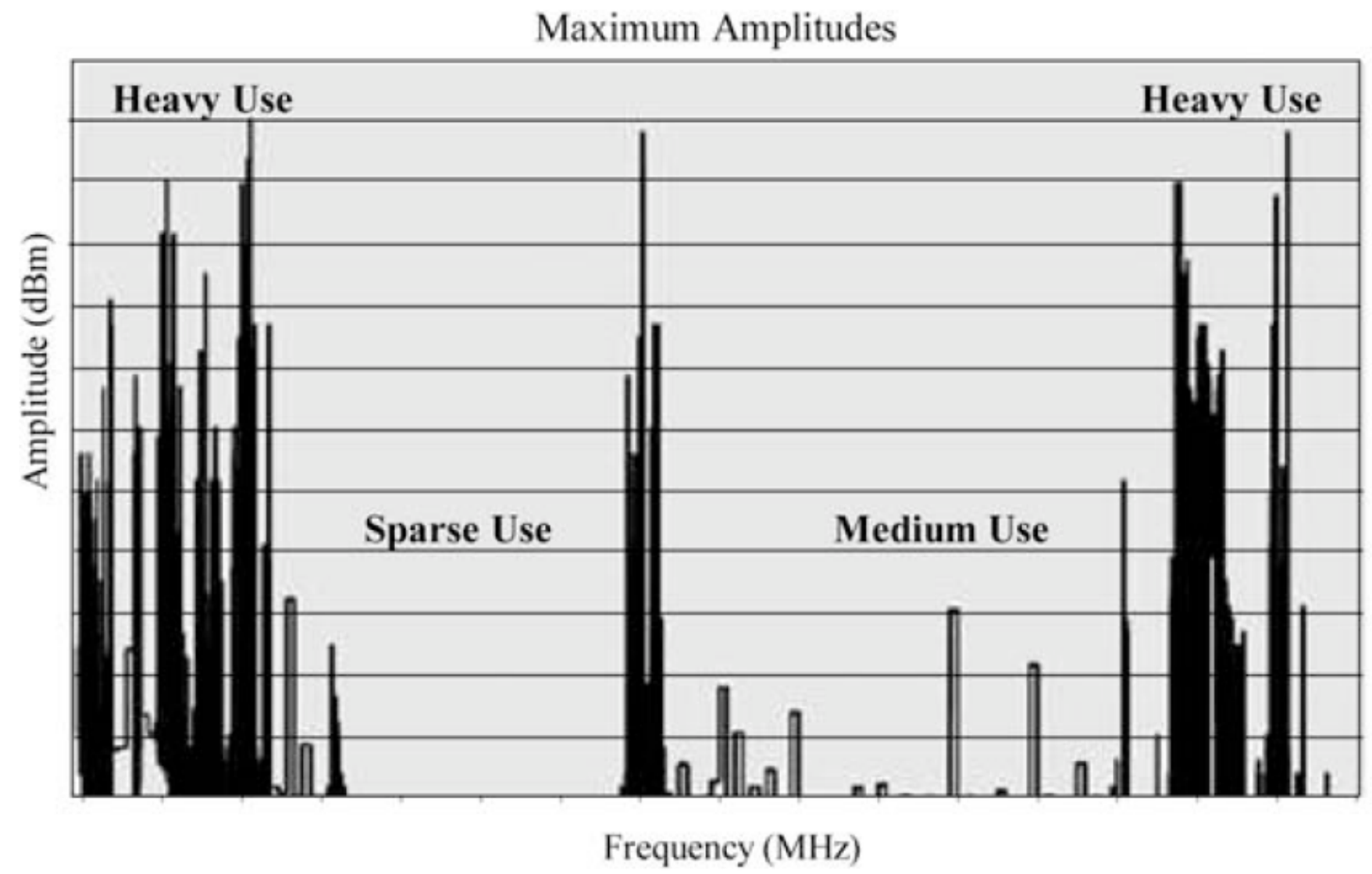

Figure 1

Spectrum utilisation chart report by Federal Communication Commission 


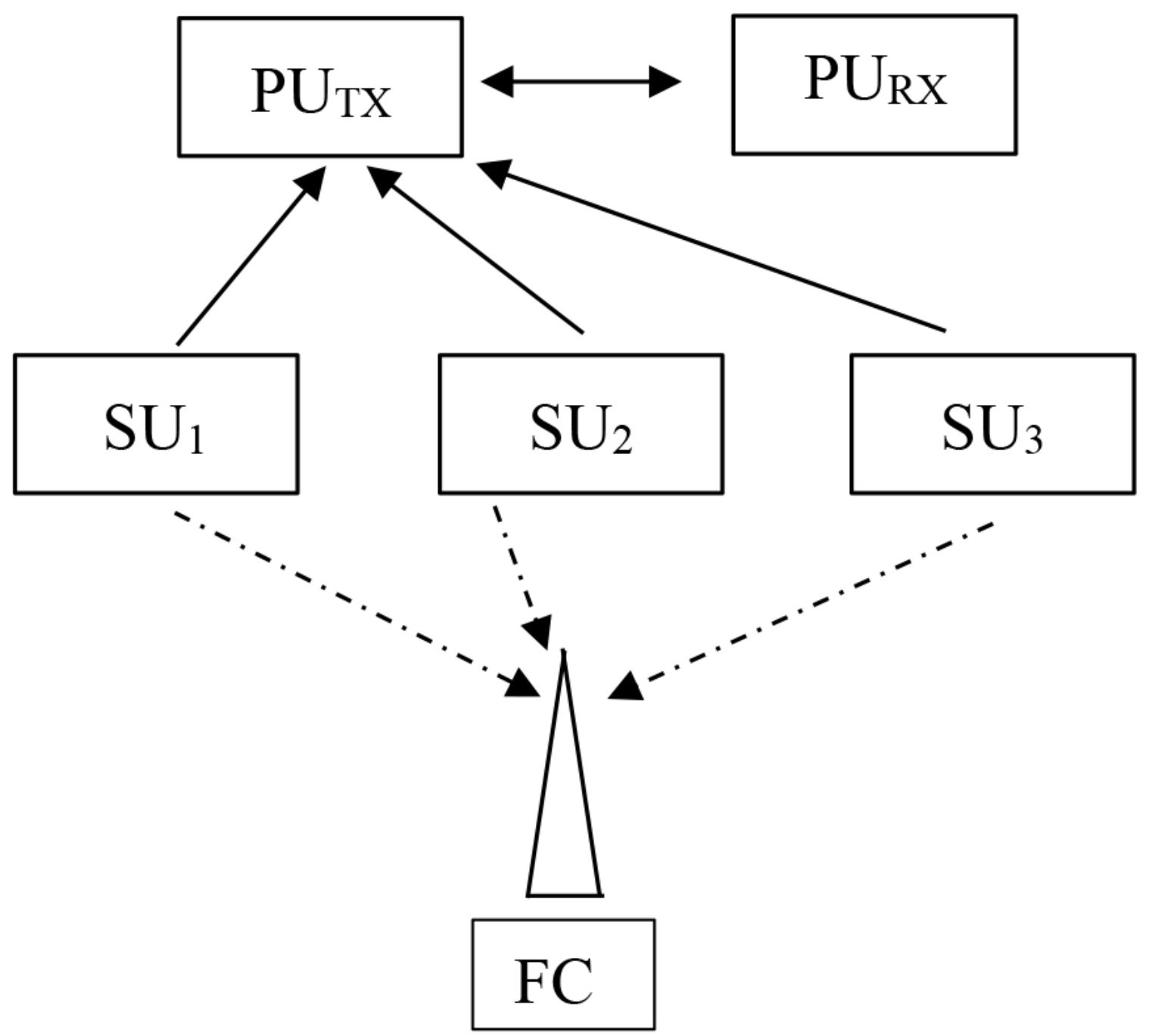

Figure 2

Conventional cooperative sensing model.

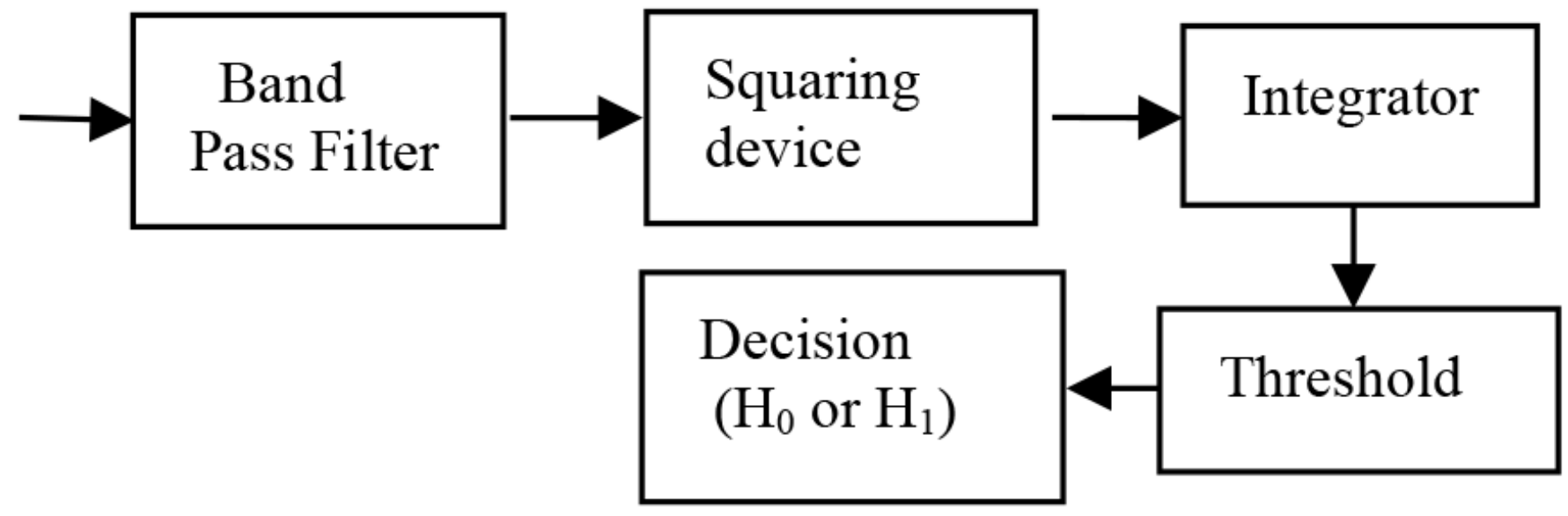

Figure 3 
Conventional energy detection technique

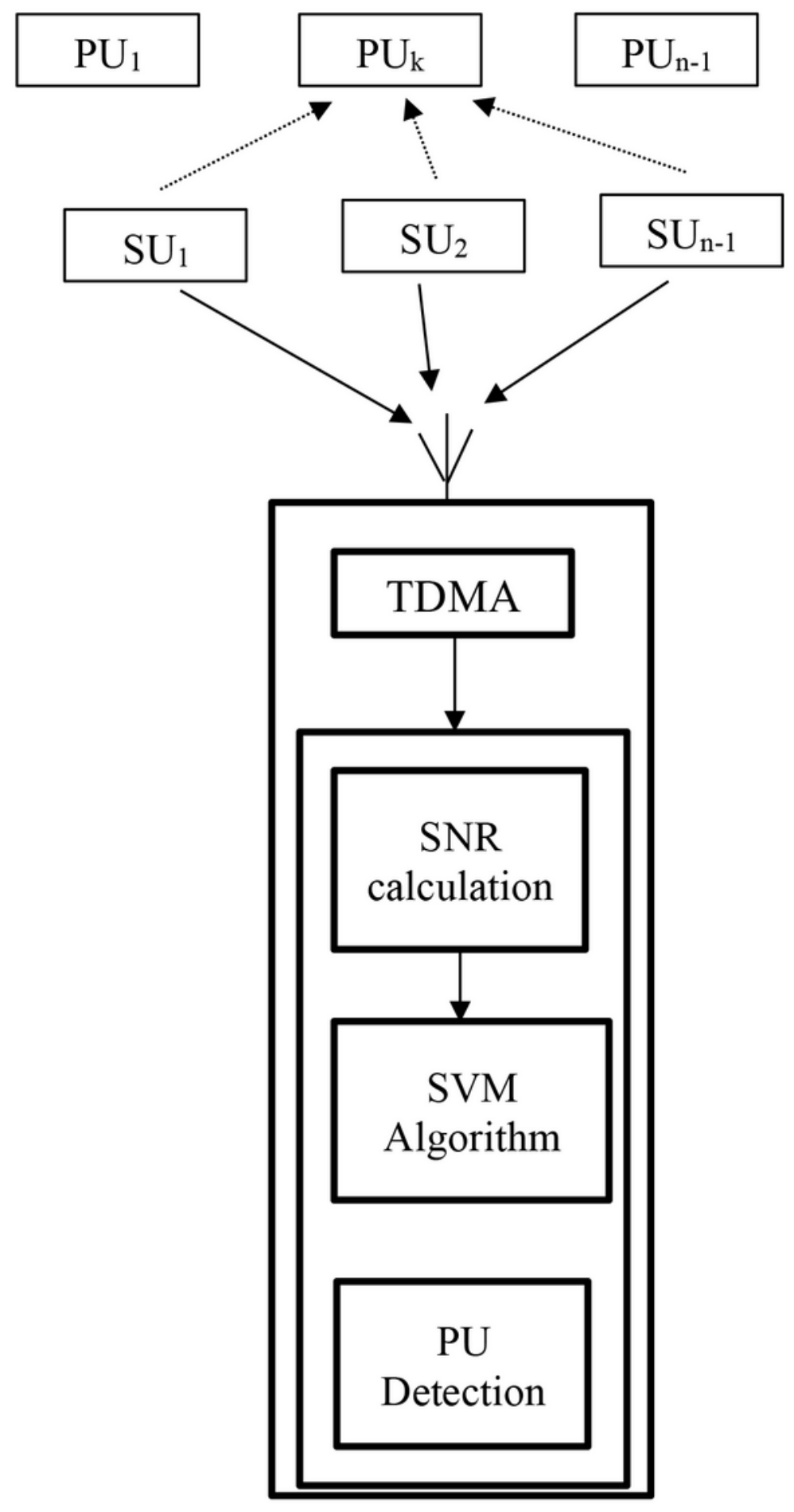

Fusion Centre

Figure 4

Proposed system model using SVM at fusion centre 


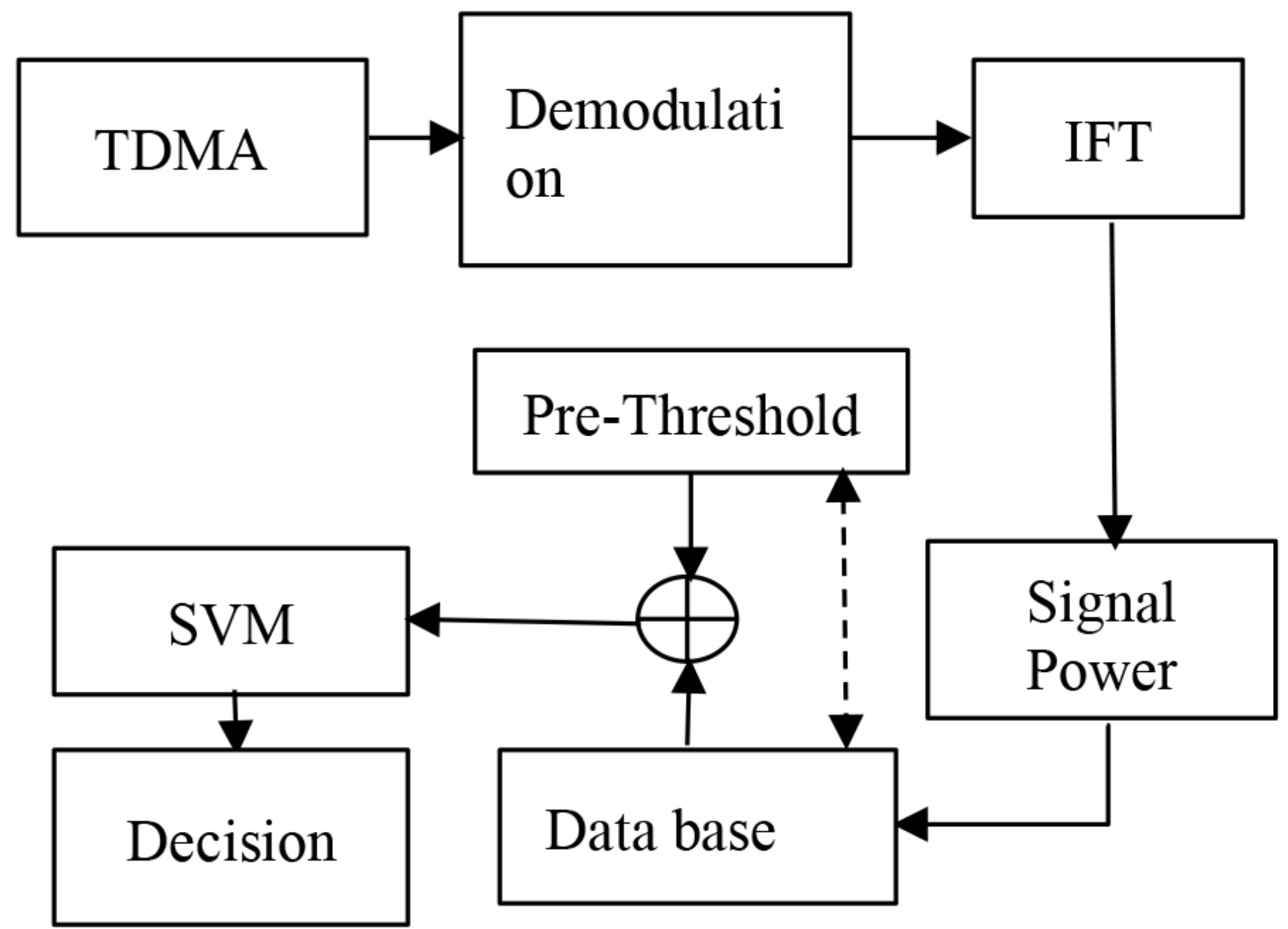

Figure 5

Proposed system block diagram of spectrum sensing using SVM 


\section{ST}

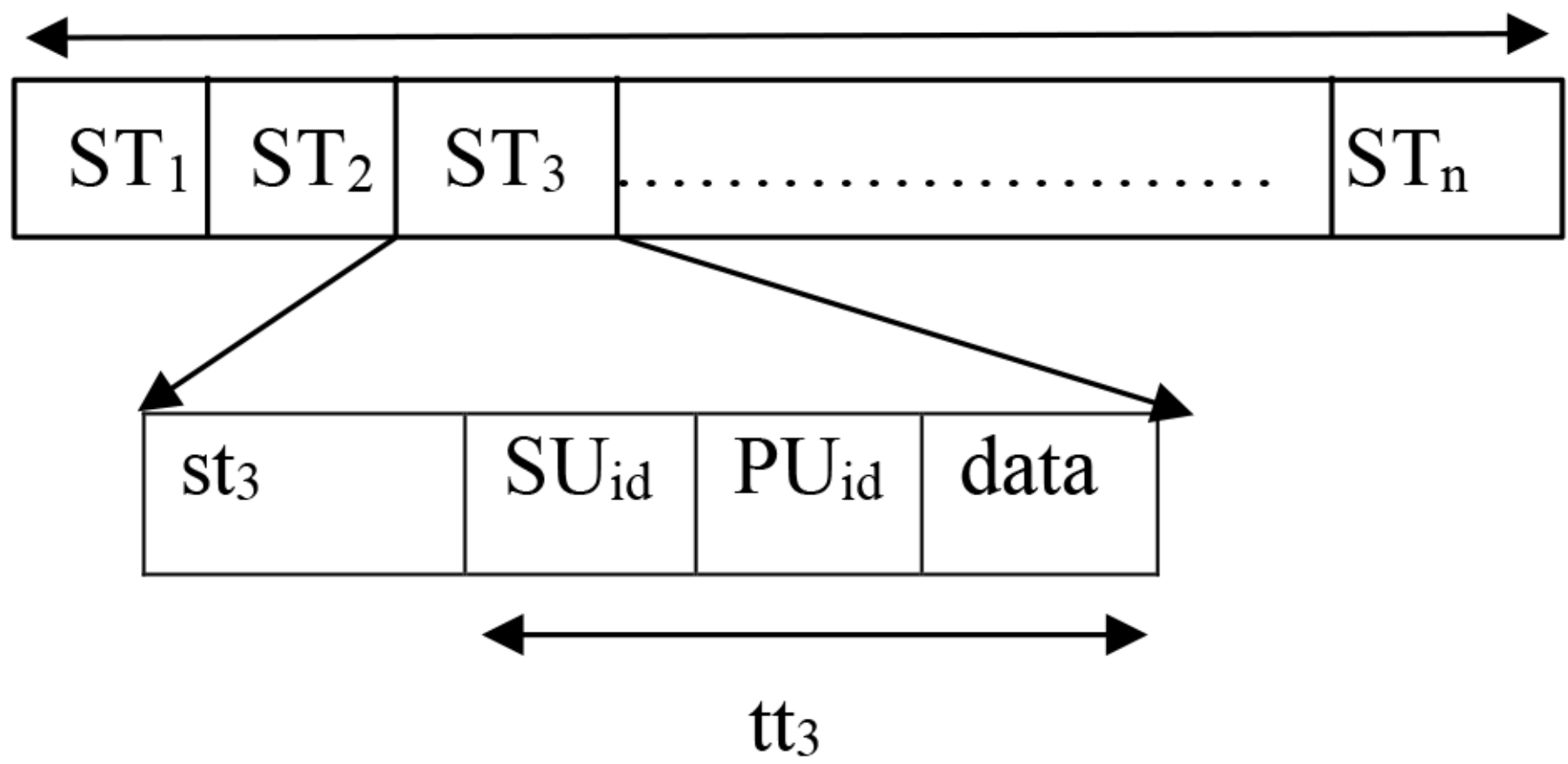

Figure 6

Sensing and transmitted signal duration frame slot 




Figure 7

Proposed system model using multi-class SVM 


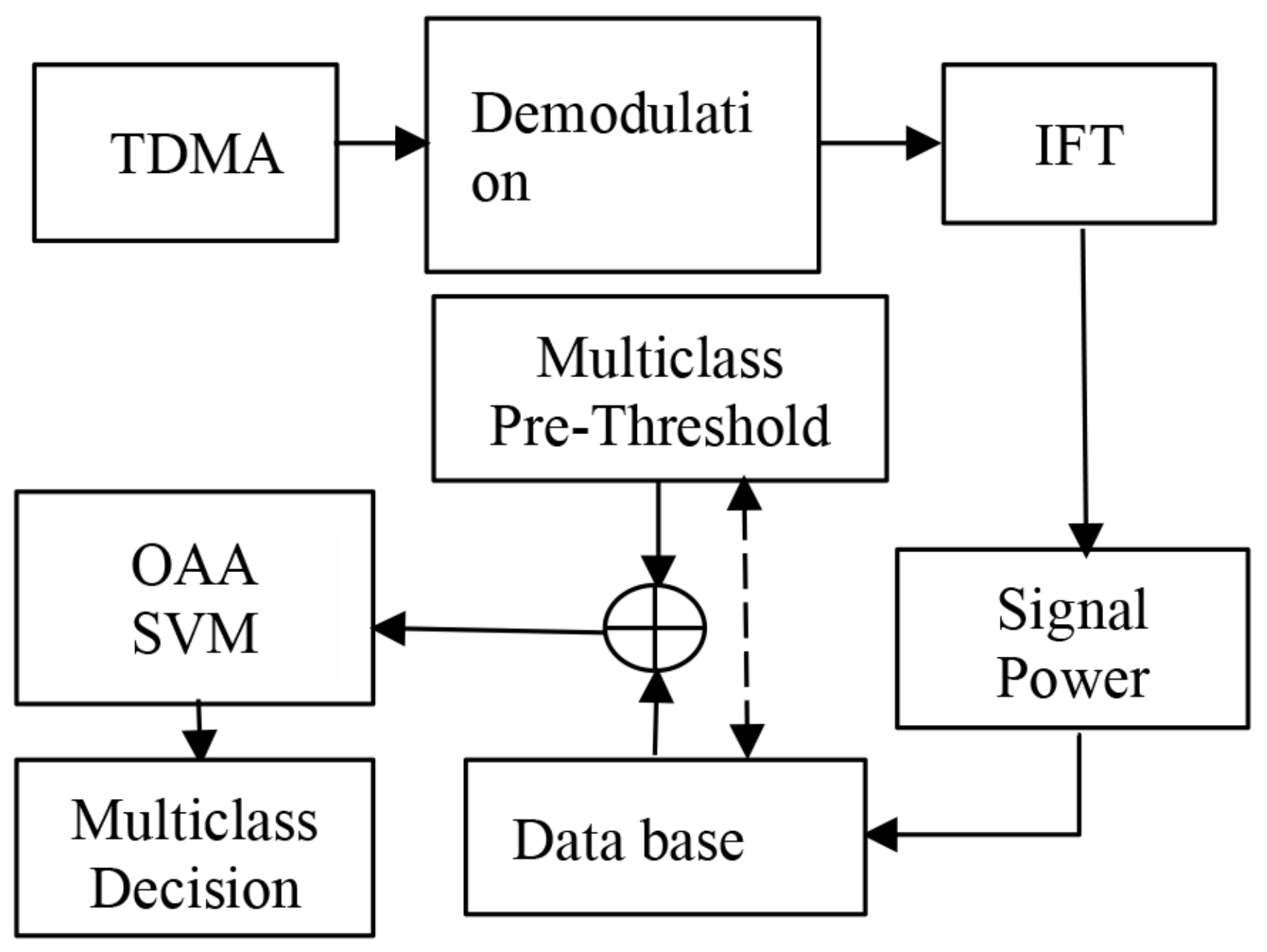

Figure 8

Proposed system block diagram using multi-class SVM 


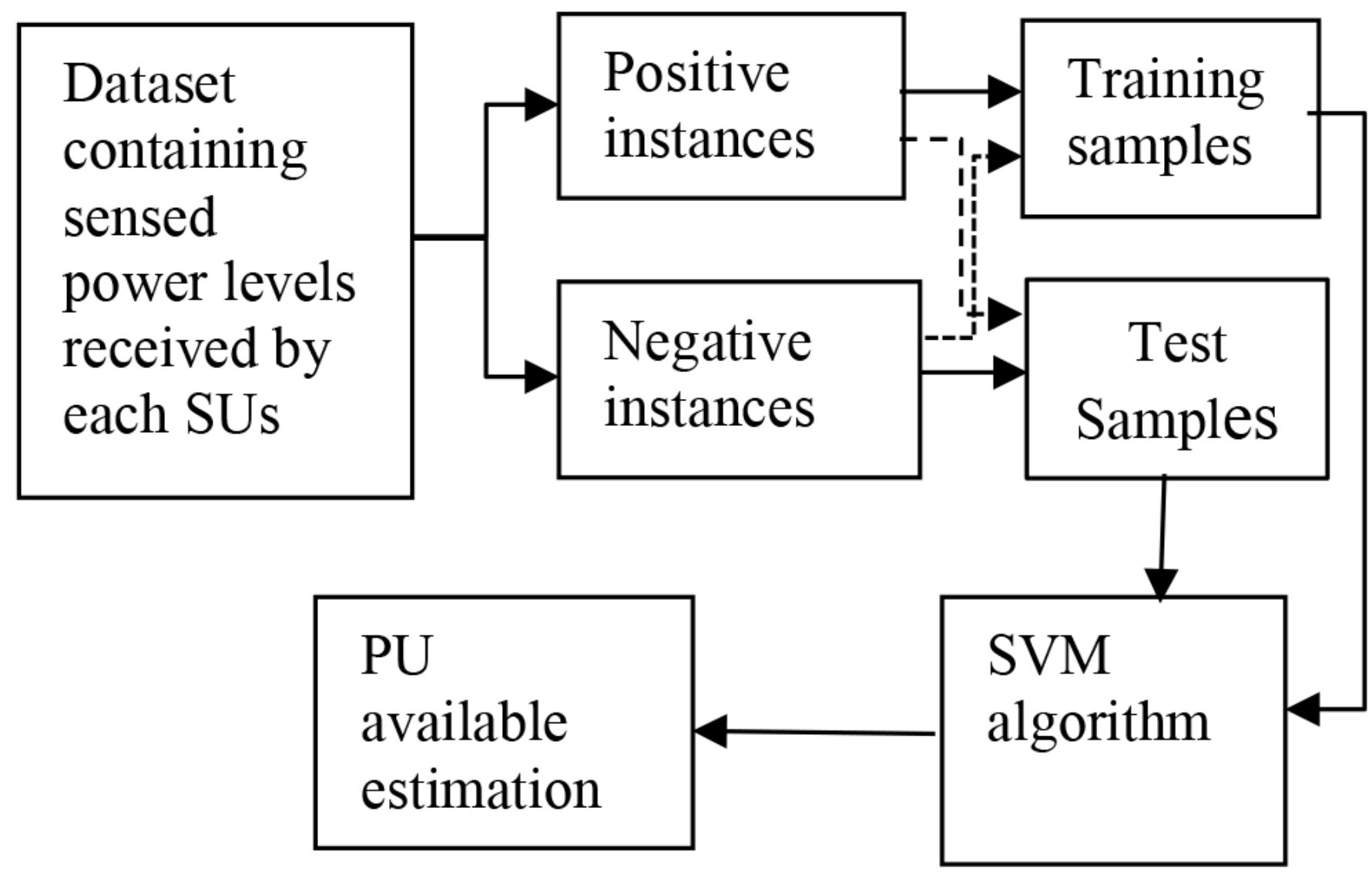

Figure 9

Supervised ML flow diagram 


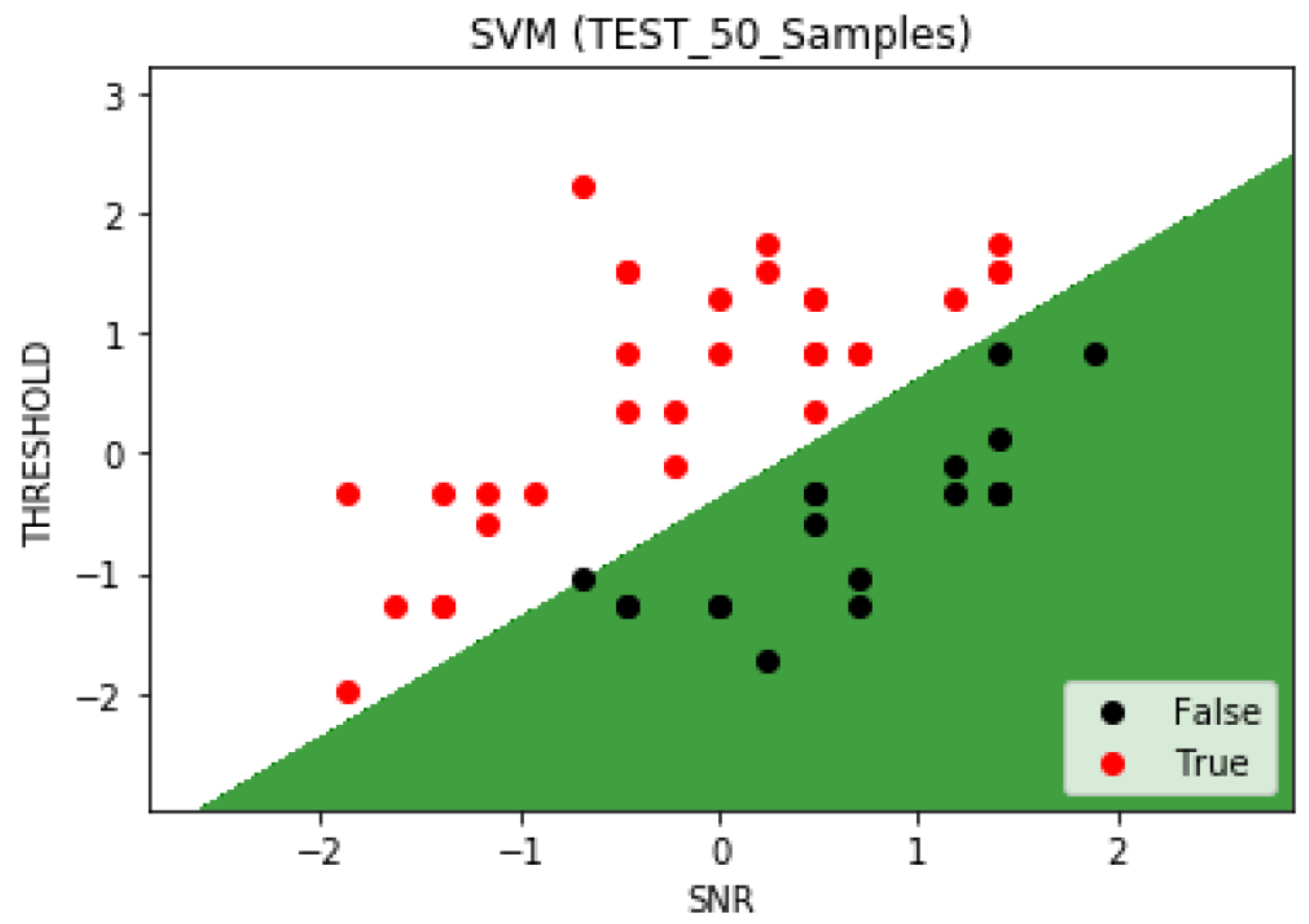

Figure 10

SVM classification for 50 SUs as test samples using linear kernel 


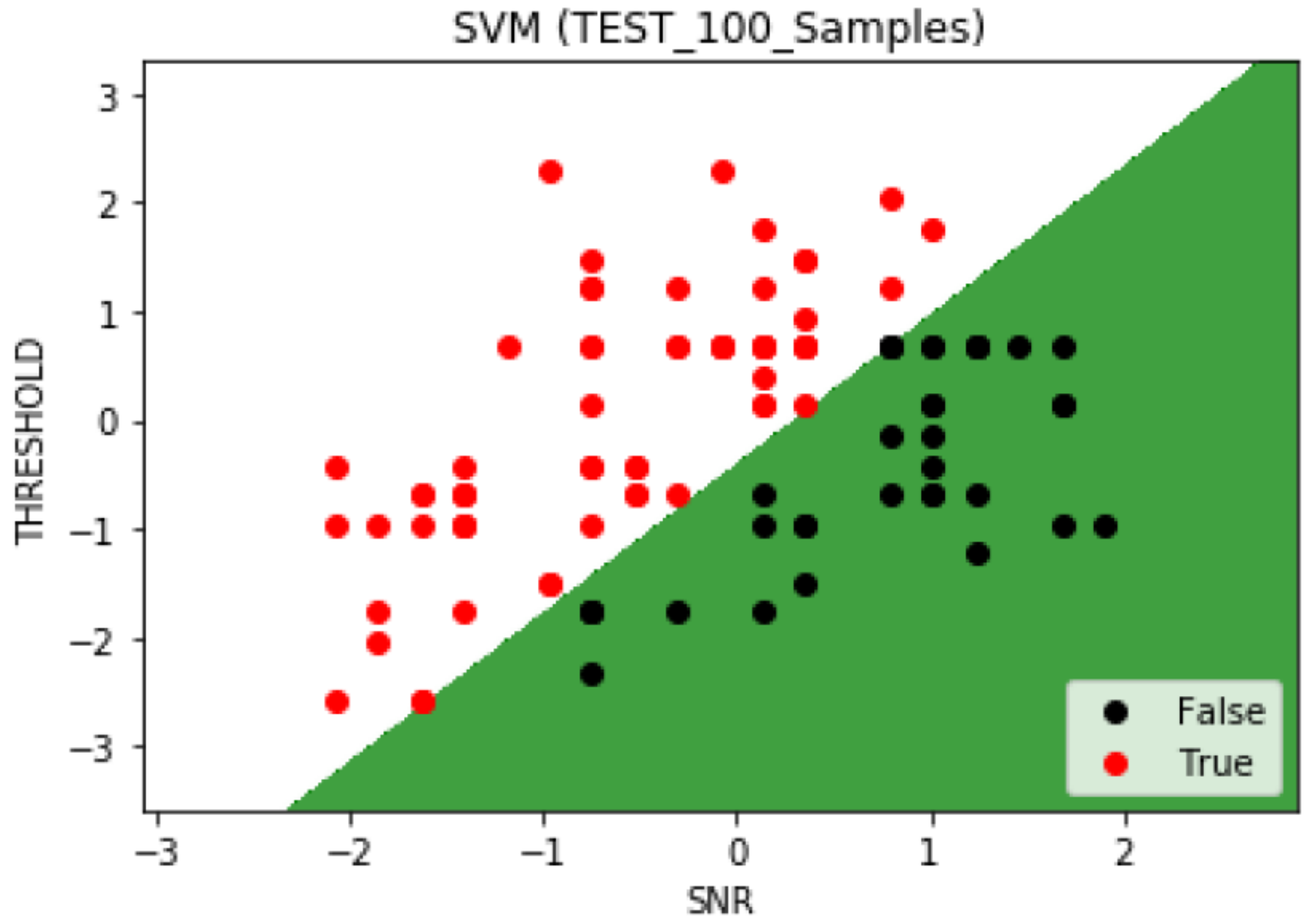

Figure 11

SVM classification for 100 SUs as test samples using linear kernel 




Figure 12

SVM classification for 125 SUs as test samples using linear kernel 


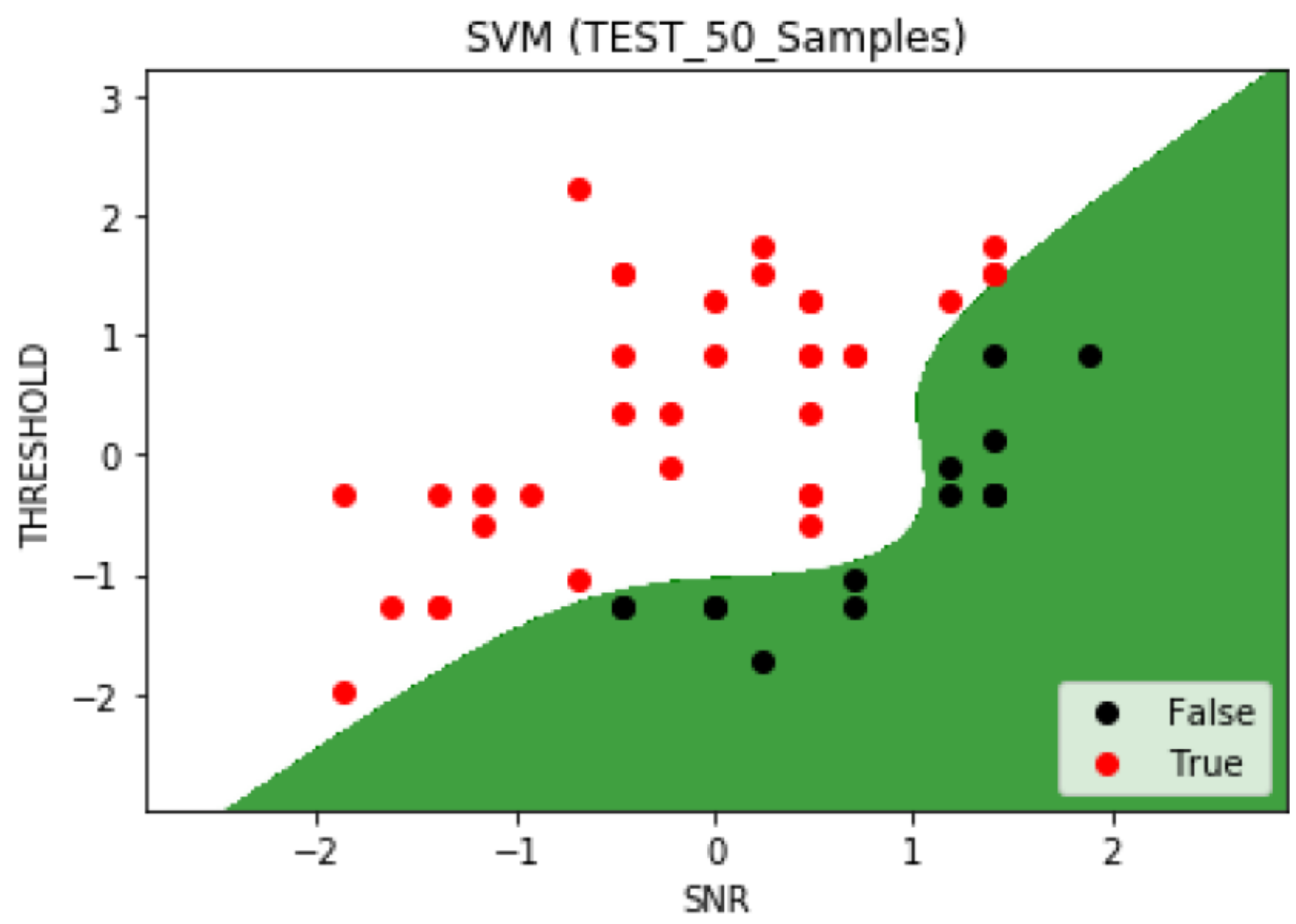

Figure 13

SVM classification for 50 SUs as test samples using polynomial kernel 


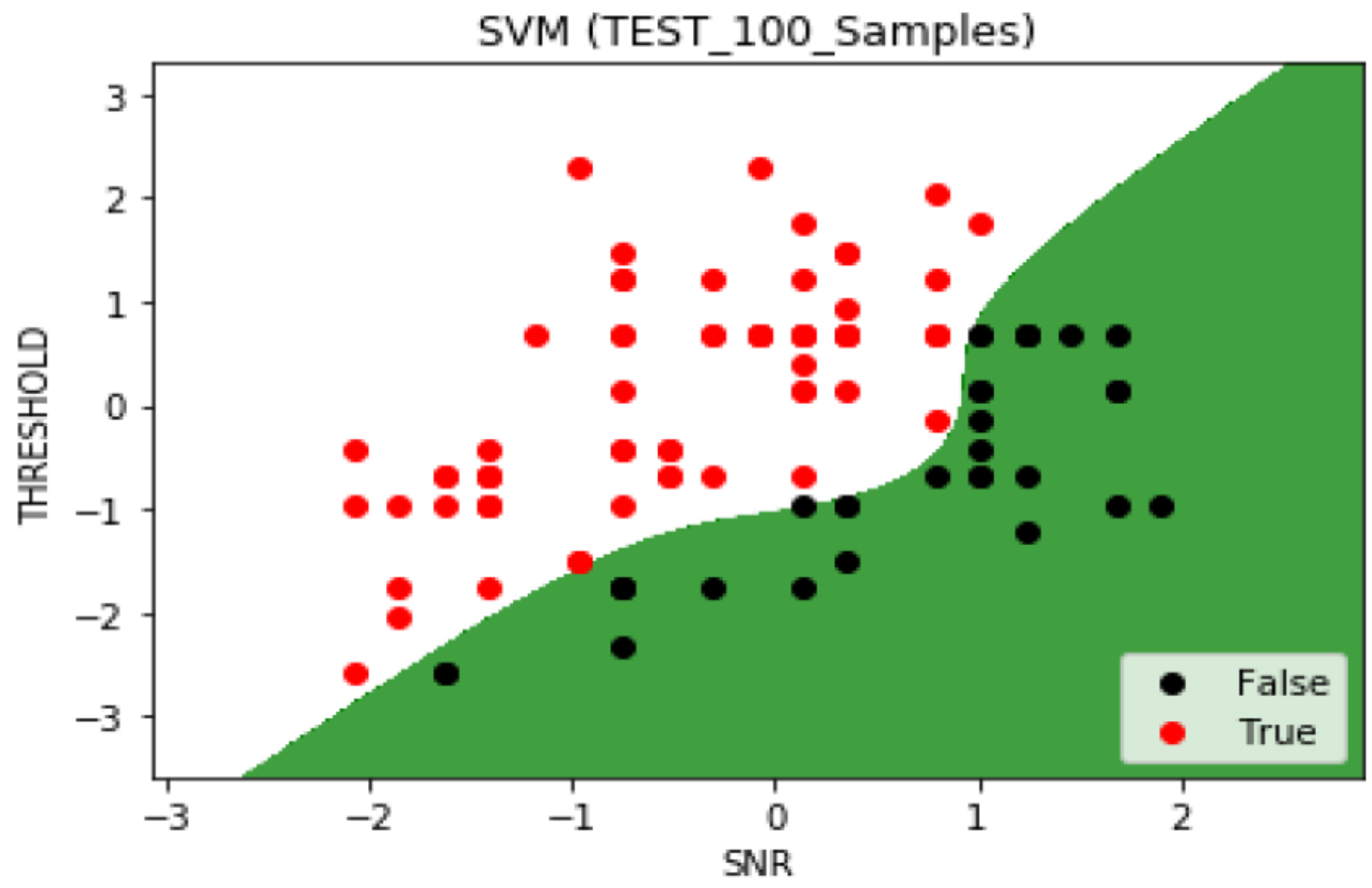

Figure 14

SVM classification for 50 SUs as test samples using polynomial kernel 


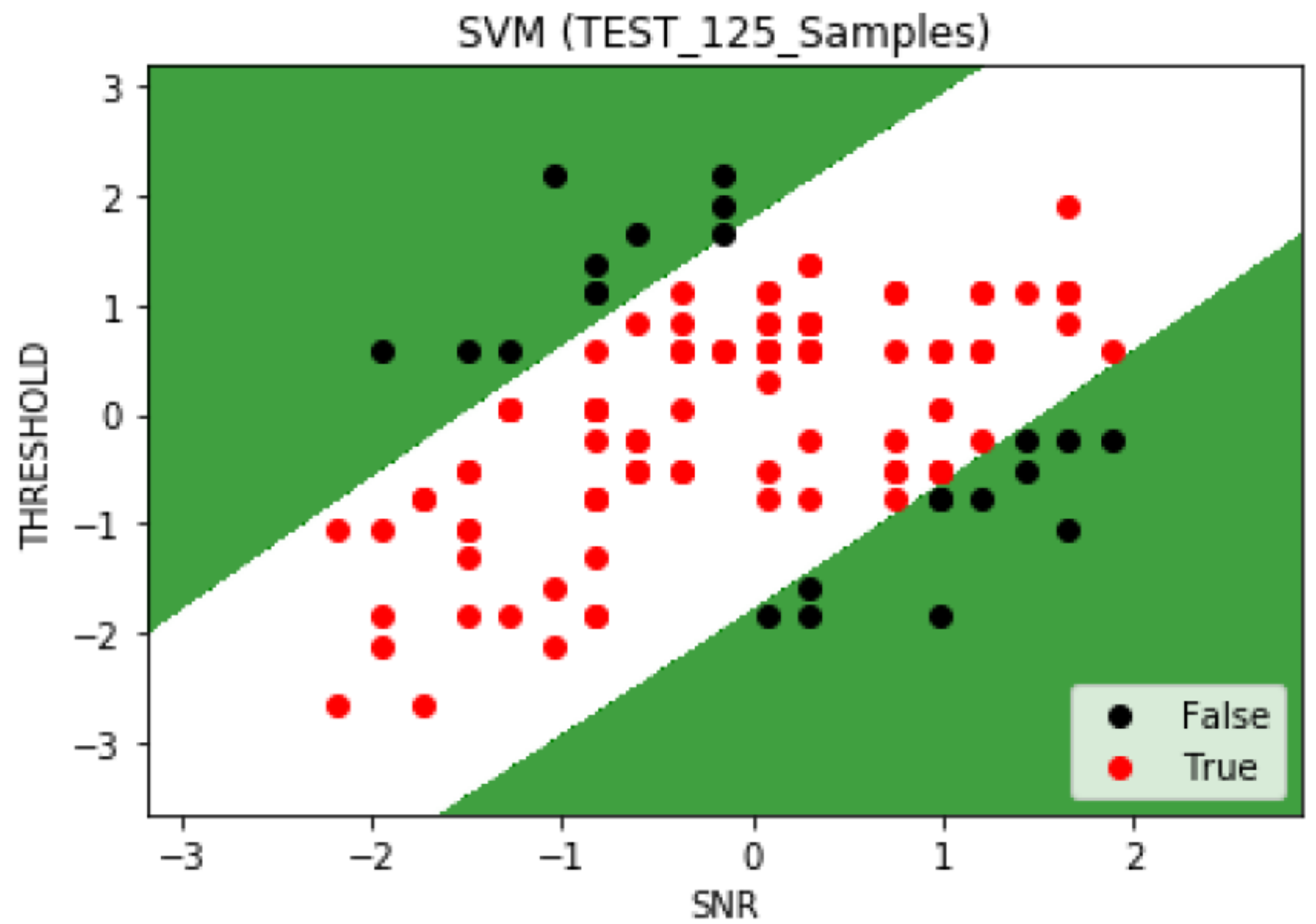

Figure 15

SVM classification for 125 SUs as test samples using polynomial kernel 


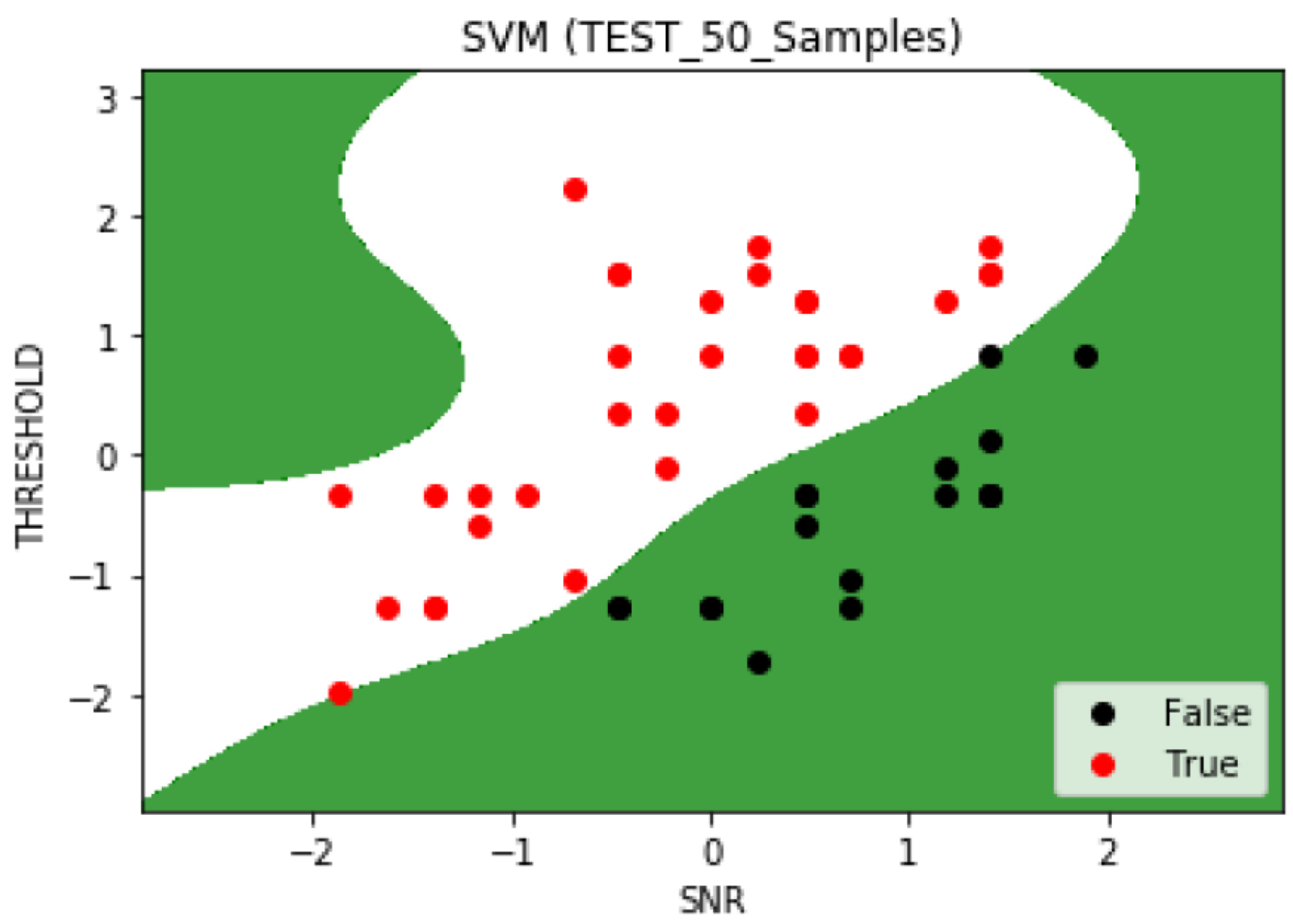

Figure 16

SVM classification for 50 SUs as test samples using RBF kernel 


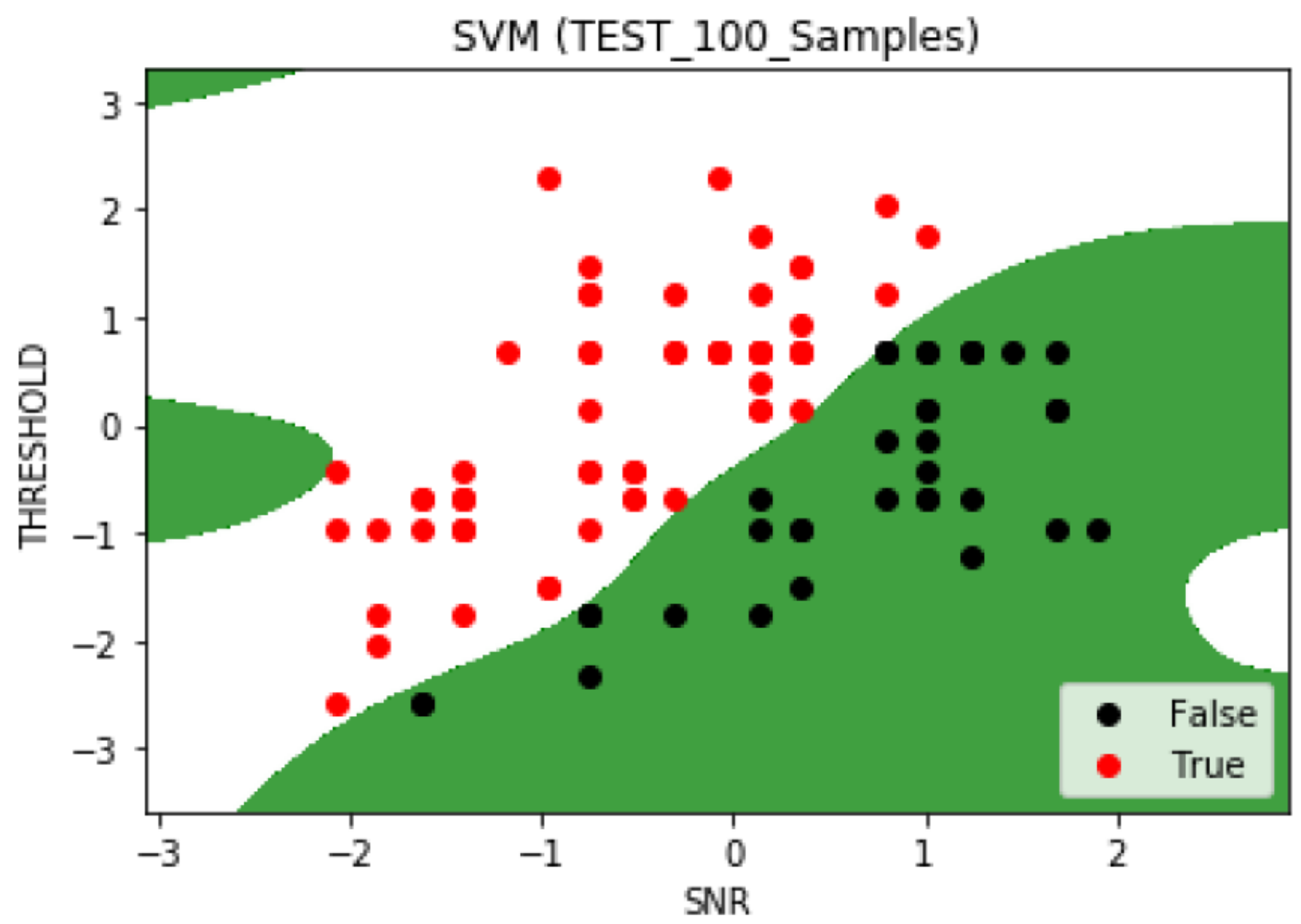

Figure 17

SVM classification for 100 SUs as test samples using RBF kernel 


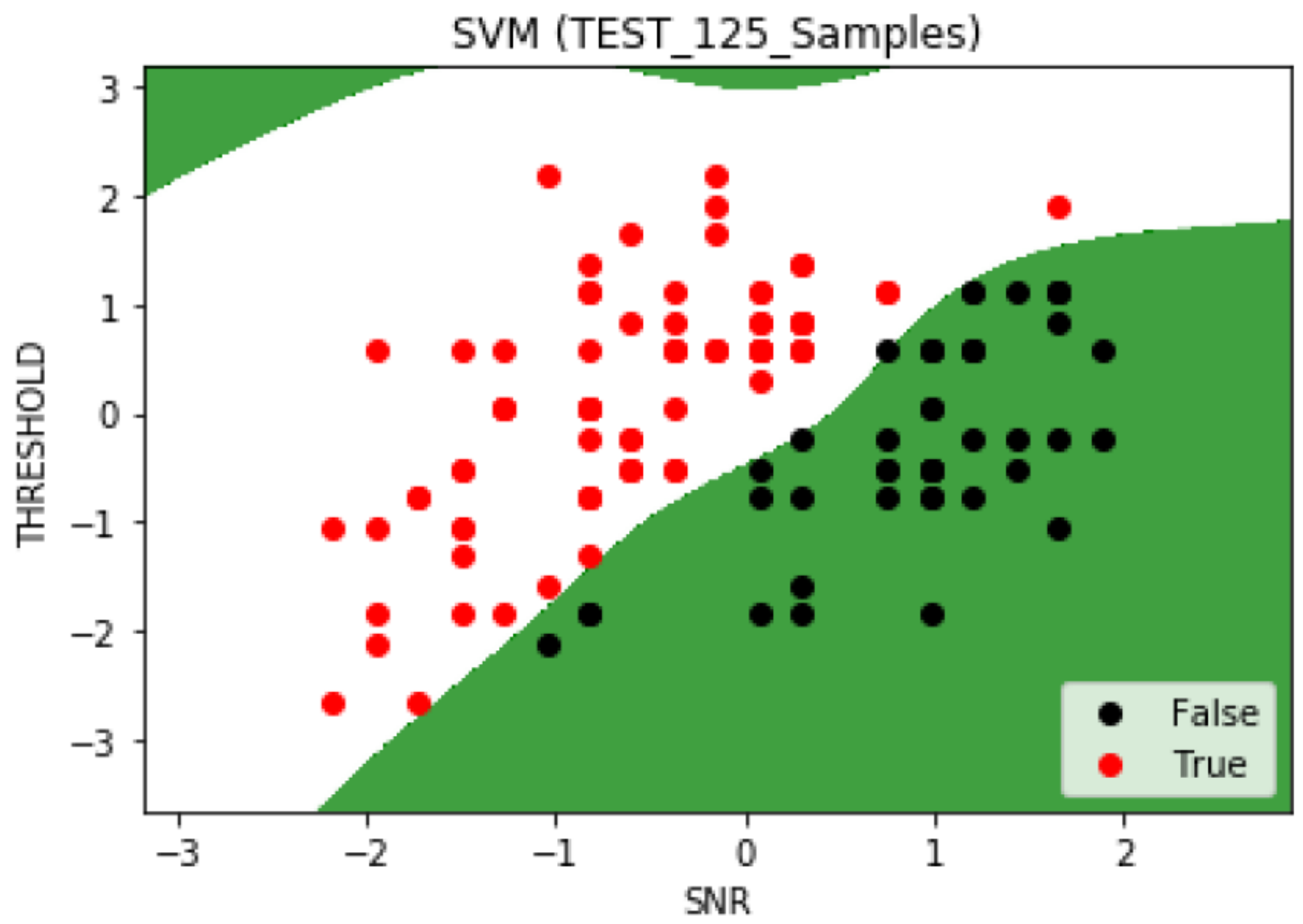

Figure 18

SVM classification for 125 SUs as test samples using RBF kernel 


\section{Percentage of Accuracy for three different classes of different kernels}

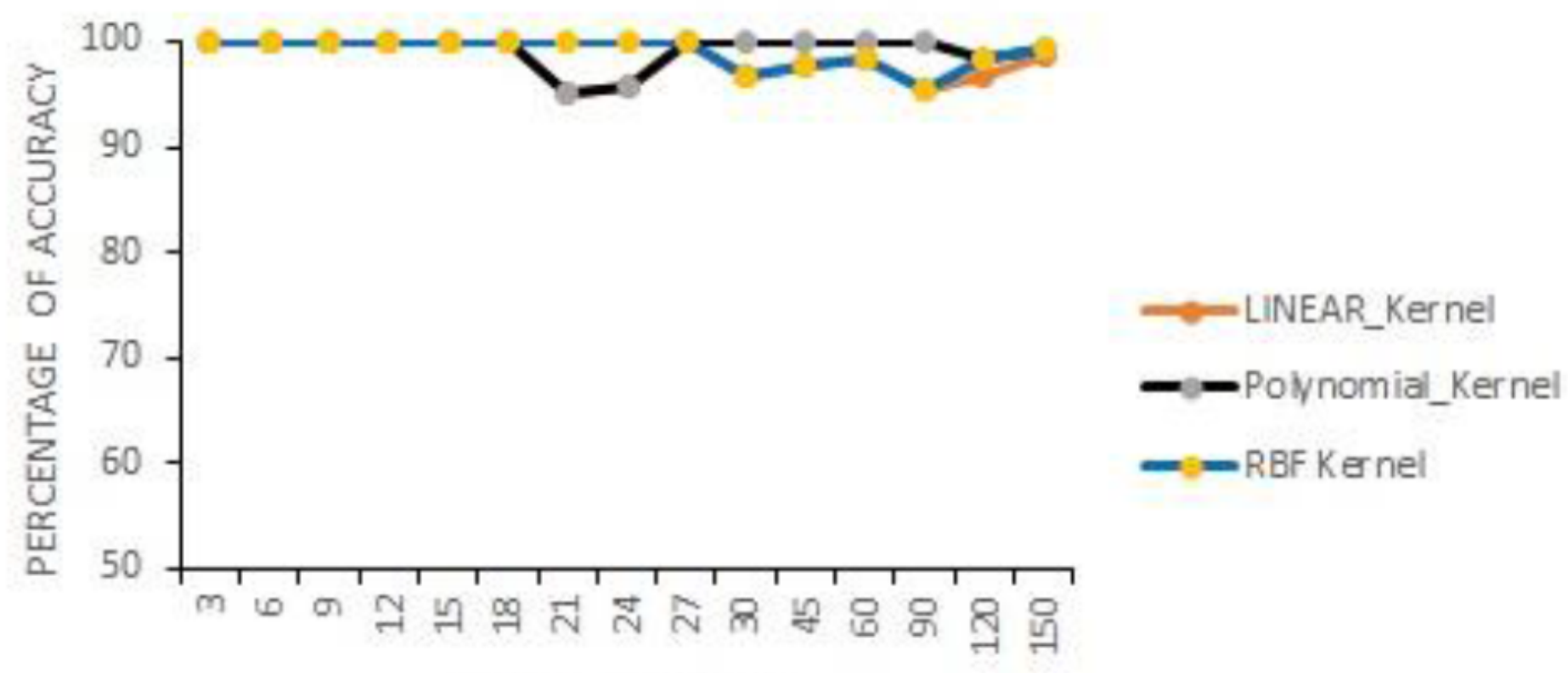

SU TEST SAMPLES

Figure 19

Percentage of accuracy of three different kernels to classify n-number of SUs by the fusion centre 




Figure 20

Percentage of false alarm of three different kernels to classify n-number of SUs sensing information by the fusion centre 


\section{Percentage of Accuracy for three different classes of different kernels}

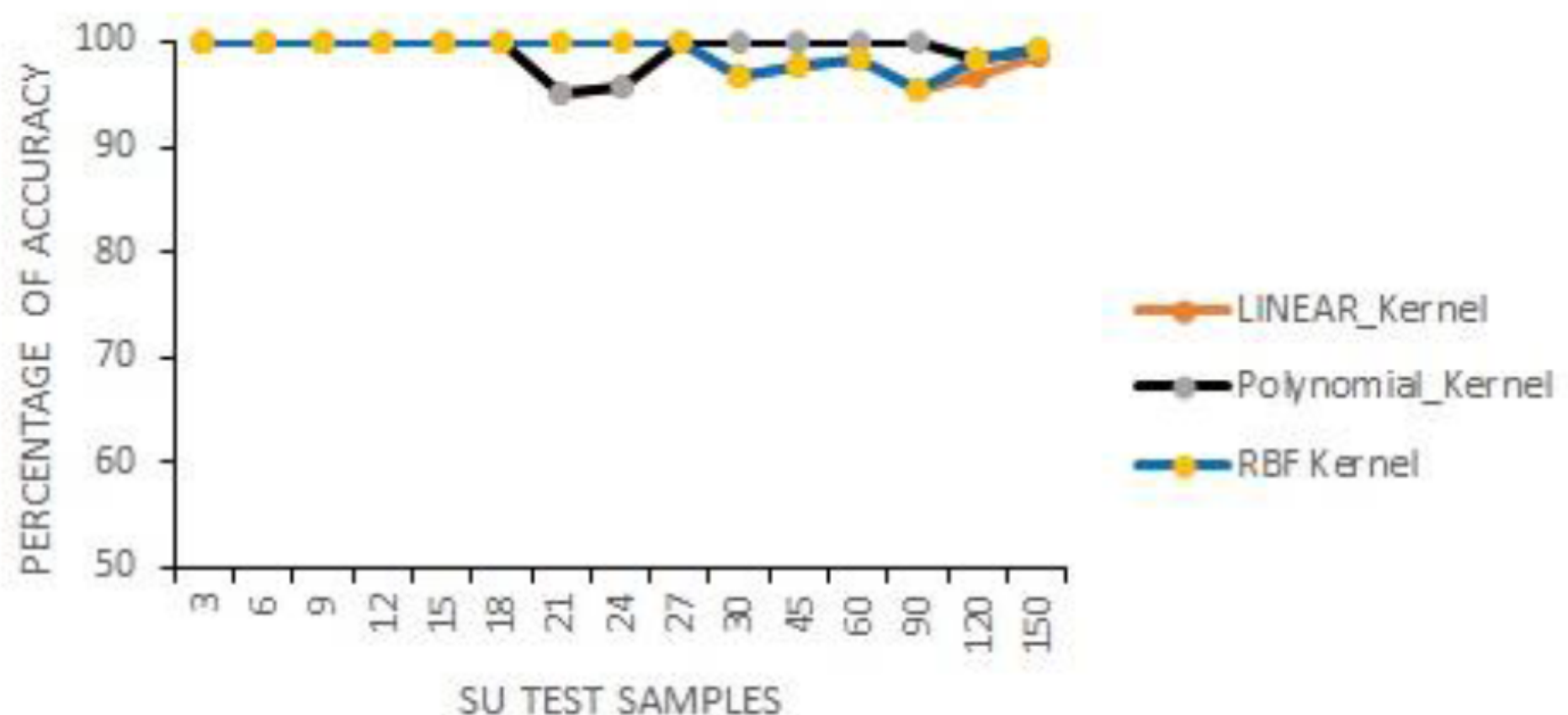

Figure 21

Percentage of accuracy for three different classes of different kernels to classify the SUs by the fusion centre. 


\section{Percentage of False alarm for three different classes using RBF kernel}



Figure 22

Percentage of false alarm for three different classes to classify the SUs by using RBF kernel 